\title{
A CONSTRUÇÃO DO PROJETO POLÍTICO PEDAGÓGICO DAS ESCOLAS DO CAMPO: UMA CONTRIBUIÇÃO AO TEMA
}

\author{
Eliana Campos POJO \\ FAECS/Campus Universitário de Abaetetuba \\ elianapojo@ufpa.br \\ Josilene Ferreira BARRETO \\ Campus Universitário de Abaetetuba/UFPA \\ jlene1@hotmail.com
}

Resumo: O presente artigo evidencia a construção do Projeto Político Pedagógico (PPP) nas escolas do campo, especificamente as que estão localizadas nas ilhas do município de Abaetetuba. Esta feitura foi uma das ações do Grupo de Estudo, Pesquisa e Extensão Sociedade Estado e Educação (GEPESEED). O município de Abaetetuba possui aproximadamente setenta e duas (72) ilhas e nessas estão distribuídas cerca de oitenta e três (83) escolas, funcionando com o atendimento escolar nos seguintes niveis de ensino: Educação Infantil, Ensino Fundamental e Ensino Médio. Desse contingente de escolas das ilhas grande parte não possui o PPP construído, o que impossibilita, entre outras situações, a de participação nos programas e ações do governo federal, que o exigem como um dos instrumentos de organização da escola. Nos termos da lei (LDB 9394/96) fica explíita a intencionalidade de que todos precisam participar da vida escolar em suas múltiplas dimensões (social, administrativa e político-pedagógica), assim a construção do PPP de uma escola, constitui-se uma aprendizagem necessária, a ser experienciada e vivenciada por toda comunidade escolar, pois é uma oportunidade em que se pode refletir sobre a intencionalidade da própria prática educativa. Somos sabedores que o projeto norteia todas as ações escolares de forma planejada e organizada e sua ausência torna a escola desfocada, sem identidade e direção, seguindo qualquer rumo e principalmente sem compromisso com o processo educativo. Foi com esse sentido político, que os encontros formativos, base da ação do GEPESEED, buscaram desenvolver estudos e o assessoramento à construção do PPP das referidas escolas, em parceria com a Secretaria Municipal de Educação do município de Abaetetuba. Sinteticamente, os encontros formativos foram assumidos como exercício da práxis, ou seja, um movimento cíclico (escola-formação-intervenção), contínuo e de reflexão sobre a prática para os gestores que estão na coordenação das escolas e com a responsabilidade na condução do trabalho pedagógico do cotidiano escolar. (FREIRE, 1996).

Palavras-chave: Projeto Político Pedagógica. Escolas do campo. Formação. 


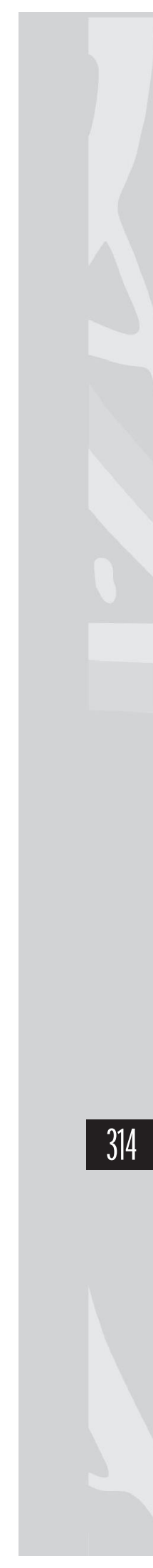

Abstract: This paper shows the construction of Political Pedagogical Project $(P P P)$ in the rural schools, especially those that are located in the islands of the city of Abaetetuba. This was work one of the actions of the Study Group and Research Society State and Education (GEPESEED). The city of Abaetetuba has approximately seventy-two (72) islands and in these are distributed approximately eighty-three (83) schools, working with school attendance in the following grade levels: Early Childhood, Elementary and Secondary Education. Of this group of islands most schools do not have PPP built, which prevents, among other situations, the participation in the programs and actions of the federal government, requiring it as an instrument of school organization. Under the law (LDB 9394/96) is the explicit intention that everyone needs to participate in school life in its multiple dimensions (social, administrative and political-pedagogical) and the construction of a PPP school, constitutes learning required to be experienced and lived throughout the school community, it is an opportunity in which they can reflect on the intentionality of their own educational practice. We are mindful that the design guides to all school actions in a planned and organized, and its absence makes the school blurry without identity and direction, following direction and mostly without any commitment to the educational process. It was in this political sense, the formative meetings, base of the action of GEPESEED, sought to develop studies and advisory services to build the PPP of these schools, in partnership with the City Department of Education of the City of Abaetetuba. Briefly, the formative meetings were undertaken as an exercise of praxis, ie, a cyclic movement (school-formation-intervention), and continuous reflection on practice for managers $w$ ho are in the schools and coordination with the responsibility to conduct the work pedagogical school routine. (Freire, 1996).

Keywords: Political Pedagogical Project. Field schools. Formation.

\section{Introdução}

O presente artigo evidencia a construção do Projeto Político Pedagógico (PPP) nas escolas do campo $^{1}$, especificamente as escolas que estão localizadas nas ilhas do município de Abaetetuba. Esta feitura foi uma das ações do Grupo de Estudo, Pesquisa e Extensão Sociedade

\footnotetext{
1 A educação do campo no município de Abaetetuba está organizada levando em consideração a distância e o tipo de área geográfica, sendo classificadas em ilhas, estradas e ramais. Porém, neste artigo iremos tratar especificamente da educação do campo nas ilhas, a ribeirinha.
} 
Estado e Educação (GEPESEED) e contou com o apoio da Secretaria Municipal de Educação e Cultura (SEMEC) desse município.

Destacamos que nesse ano, o grupo de pesquisa vem desenvolvendo em uma de suas linhas de pesquisa (Movimentos Sociais e Educação do Campo), o projeto de pesquisa intitulado Travessias, identidades e saberes das águas - Cartografia de saberes de populações ribeirinhas no município de Abaetetuba numa travessia pelas águas, rios e florestas que compõe o cenário amazônico desse município, buscando problematizar o papel do Estado no desenvolvimento das Políticas Educacionais Púbicas para as populações do campo, tomando como foco de análise a gestão municipal e as experiências educativas nas escolas do campo. Assim, a ação formativa junto aos gestores foi uma ação de extensão, que nos permitiu conhecer e aprofundar as questões educacionais na área rural desse município, no território das ilhas, local onde se realizou a referida pesquisa.

Cabe esclarecer que o município de Abaetetuba possui aproximadamente setenta e duas (72) ilhas e nessas estão distribuídas cerca de oitenta e três (83) escolas, funcionando com o atendimento escolar nos seguintes níveis de ensino: Educação Infantil, Ensino Fundamental e Ensino Médio², sendo que esse último nível de ensino constitui-se em anexos das escolas estaduais que ficam localizadas na parte urbana da cidade. Desse contingente escolar nas ilhas, grande parte não possui o PPP construído, o que impossibilita, entre outras situações, a participação nos programas e ações do governo federal que o exigem como um dos instrumentos de normatização e organização da escola.

A escolha da ação formativa focalizada no PPP, justifica-se dada sua importância político-pedagógica visando alterações significativas no interior das escolas. Sabemos que o PPP é uma exigência legal amparada pela legislação educacional (LDB) e também como marco regulatório dentro do sistema de ensino (o PPP é um dos documentos exigidos pelos conselhos de educação para ato autorizativo de uma escola). No entanto,

\footnotetext{
${ }^{2}$ Destacamos como particularidade das escolas do campo nesse município a concentração de dois sistemas de ensino, ou seja, o sistema de ensino estadual nas ilhas de Abaetetuba concentra a escolarização do $6^{\circ}$ ao $9^{\circ}$ ano e Ensino Médio na forma de ensino regular e no ensino modular funcionando em parceria com o sistema municipal. E na mesma escola há o atendimento municipal com a Educação Infantil e o Fundamental $\left(1^{\circ}\right.$ ao $5^{\circ}$ ano).
} 
muito mais que sua exigência regulatória para o sistema educacional, sua importância se expande para o desenvolvimento de um trabalho educativo planejado e participativo, de responsabilidade compartilhada e, principalmente, de uma escola com clareza político-pedagógica da sua função social naquela comunidade. Desse modo, a construção do PPP ratifica o princípio da gestão democrática postulado pela lei magna e confirmada na Lei de Diretrizes e Bases da Educação Nacional (LDB) 9.394/96, ao instituir para os sistemas de ensino o desdobramento do como proceder para que de fato se almeje o que está citado legalmente, conforme consta no art.14:

Os sistemas de ensino definirão as normas da gestão democrática do ensino público na educação básica, de acordo com as peculiaridades e conforme os seguintes princípios:

I - participação dos profissionais da educação na elaboração do projeto pedagógico da escola.

II - participação das comunidades escolar e local em conselhos escolares ou equivalentes.

Nos termos da lei, fica explícita a intencionalidade, de que todos precisam participar da vida escolar, em suas múltiplas dimensões (social, administrativa, político-pedagógica) e nessa construção, o PPP de uma escola constitui-se em aprendizagem necessária, a ser experienciada e vivenciada por toda comunidade escolar, pois é uma oportunidade de refletir sobre a intencionalidade de sua prática educativa. Somos sabedores que o projeto norteia todas as ações escolares de forma planejada e organizada e, sem o projeto a escola fica desfocada coletivamente, sem direção e principalmente sem clareza dos objetivos condizentes com as necessidades reais por que passa a escola. Dessa forma, por meio do PPP se intenciona um trabalho pedagógico assumido com base nos seguintes pressupostos:

- democratização do processo de planejamento;

- melhoria da qualidade social de ensino;

- prática educativa alimentada pelas experiências socioculturais que estão na comunidade;

- avaliação institucional contínua da escola; 
- qualificação e desenvolvimento do pessoal técnico-administrativo e docente;

- agilização das atividades administrativo-pedagógicas e, ainda,

- efetividade do cumprimento dos fins da escola (VEIGA, 2003).

No entanto, para que tais pressupostos estejam presentes e exercitados no cotidiano escolar, as relações sociais que compõem a organização escolar precisam ser conflitadas e consensuadas pelo coletivo dos sujeitos que fazem a escola. Isso significa dar credibilidade ao saber e fazer de todos; envolver o coletivo dos profissionais; discutir e dirimir problemáticas interpessoais que possam existir, enfim, tornar o cotidiano escolar e seus conflitos como condicionantes do processo educativo da própria escola.

Alguns momentos de vivência pedagógica no cotidiano escolar são indispensáveis. Os momentos formativos e de intervenção pelos envolvidos no processo educativo (coordenadores pedagógicos, docentes e a comunidade escolar, de modo geral) são partes constituintes e basilares para a organização das práticas pedagógicas na construção de um currículo coletivo, interdisciplinar e coerente com as concepções democráticas de educação.

Outras ações importantes estão na organização do trabalho pedagógico, que se constitui pelo planejamento didático durante todo o ano letivo; na sistematização de documentos pedagógicos como os dos conselhos de classe, da diagnose das turmas, dos projetos didáticos e dos planos de ensino das turmas; na interlocução entre a gestão da escola e a comunidade escolar tratando das situações pedagógicas e administrativas; a escuta da comunidade sobre a educação dispensada a ela; na orientação pedagógica processual junto aos coordenadores e docentes, entre outros aspectos. Esses aparatos pedagógicos podem ser elementos problematizadores das ações educativas no interior da escola, assim como se constituem como dinamizadores das práticas coletivas e integradas.

Estabelecer uma sequência didática e formativa para a atuação do conselho escolar, é outro fator importante para que a escola atue numa dinâmica democrática, que favoreça processos coletivos e participativos. Tais discussões no cotidiano escolar, podem ser indicativos para possíveis mudanças das práticas educativas e, de alguma forma, corrobora para a

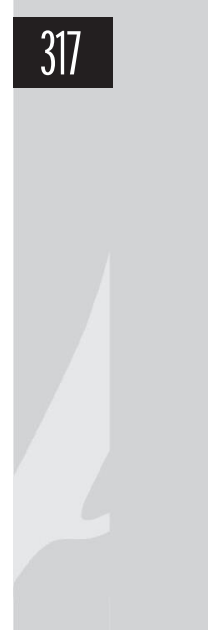


efetiva formulação de projetos político-pedagógicos vivos, em ação, ou seja, a organização do cotidiano escolar por meio do PPP, constitui-se em trabalho pedagógico de retroalimentação da prática educativa (da escola) e das várias interlocuções, com o currículo vivido/vivo em cada um dos espaços educativos.

Com base em tais considerações sobre o PPP, a estratégia metodológica dos momentos formativos junto aos gestore $\mathrm{s}^{3}$ e professores durante o percurso das atividades e ações, foi direcionada com base nos seguintes pressupostos:

O diálogo. Por ele, enfatizamos a autonomia dos protagonistas da escola (gestores, professores e demais profissionais) como fundamental para instaurar outras práticas educativas em seu interior, por meio da discussão sobre a realidade do contexto educacional da escola e da comunidade local, para que os sujeitos visualizem a participação efetiva da comunidade escolar na construção do projeto pedagógico e do currículo.

Valorização da comunidade escolar e seus pontos de vista. A partir da compreensão dos sujeitos se constrói conhecimentos e se encaminha soluções, ou seja, para a construção do PPP é essencial saber o que as pessoas pensam sobre a escola, o que compreendem sobre o PPP, que pontos de vistas possuem sobre a educação e a escolarização entre outros, para que seja compreendido os significados e sentidos do projeto.

Tessituras de construção e sistematização do projeto com a participação da comunidade escolar. É importante que a construção seja evidenciada por todos tanto durante o processo (comunicação eficiente sobre as reuniões, estudos e encontros), quanto como o produto, oriundo da vivência de construção do PPP (evidenciar o acompanhamento das ações e atividades, assim como, os momentos de avaliação).

Para o desenvolvimento dessa vivência de construção do PPP nas escolas do campo, partimos de um plano de ação com quatro encontros

\footnotetext{
${ }^{3} \mathrm{Na}$ Secretaria Municipal de Educação desse município, os gestores são identificados como 'responsáveis'. Estes são profissionais do magistério que desempenham atividades da docência (num turno) e de administração (noutro turno) e atuam em escolas pequenas como as escolas do campo consideradas anexos de escolas urbanas assumindo a responsabilidade de direção nesses anexos em comunidades rurais (estradas, ilhas e ramais). Nesse texto adotaremos a nomenclatura gestores, que são os responsáveis por escolas pequenas e/ou anexos.
} 
formativos junto aos gestores e professores num período de um semestre. Tais encontros, enfatizaram aspectos como: a importância do PPP para a prática educativa; o sentido da escola 'no e do campo'; o valor das aprendizagens pelo coletivo da escola; o passo a passo de construção do PPP; a participação da comunidade educativa como exercício cidadão entre outros.

Inicialmente realizamos os encontros no espaço do Campus de Abaetetuba e, posteriormente, realizamos os encontros em escolas das ilhas. Por meio dos encontros realizados, pudemos evidenciar que em relação à concepção, muitos gestores têm conhecimento sobre o que é o PPP e os procedimentos necessários para sua construção na escola, porém, ainda assim, percebemos as dificuldades que os mesmos sentem em produzi-lo, e entre estas foi destacada a falta de orientação e acompanhamento técnico e pedagógico por parte da secretaria de educação, a falta de tempo para estudarem e se reunirem, a ausência dos pais e da comunidade para a elaboração do projeto, entre outros aspectos.

A certeza do como fazer que expressam deverá estar aliado aos desafios da construção pela comunidade escolar por meio do esforço responsável e amoroso com o ato de educar, que no dizer de FREIRE (1996, p. 22) significa "criar as possibilidades para a sua produção ou a sua construção”.

Durante os encontros, a ação formativa acentuou a importância dos saberes da sociodiversidade do campo, pois compreendemos que a construção do PPP nas escolas do campo é intrínseca a relação da escola com a comunidade e com os aspectos socioculturais que envolvem o cotidiano das escolas (as relações que envolvem o trabalho, a terra, a educação, os modos de vida) haja vista este contexto diz respeito a vida dos sujeitos de ilhas/campo.

Diante de questionamentos e relatos dos participantes do tipo "como iniciar o PPP?" "não chega até aqui as informações" e "se ajudarem nós vamos fazer," verificamos que a construção do PPP nas escolas do campo (ilhas) ainda é um desafio para a maioria dos responsáveis por essas escolas, o que leva a pensar que a formação continuada e, até mesmo, a reflexão acerca da importância do PPP para o contexto escolar, ainda é algo a ser discutido. 
O PPP numa escola do campo só tem sentido se enraizado pela crença de que o direito à educação precisa fazer diferença na vida, ou seja:

se a escolarização não é toda a educação a que temos direito, ela é um direito social e humano fundamental. Quanto mais se afirma a especificidade do campo mais se afirma a especificidade da educação e da escola do campo. Mais se torna urgente um pensamento educacional e uma cultura escolar e docente que se alimentem dessa dinâmica formadora. Também mais se afirma a necessidade de equacionar a função social da educação e da escola em um projeto de inserção do campo no conjunto da sociedade (ARROYO; CALDART; MOLINA, 2004, p. 13).

Portanto, nesse processo de feitura do PPP, tivemos uma oportunidade formativa junto aos responsáveis das escolas ribeirinhas de Abaetetuba que ensejou o estudo coletivo, a discussão das questões que envolvem a educação do campo, o exercício de uma aprendizagem significativa junto a educadores que atuam no campo deste município, possibilitando produzir cientificamente na interação com a diversidade sociocultural dos sujeitos da micro-região do Baixo Tocantins.

\section{Encontros Formativos: percurso para a construção dos projetos político-pedagógicos das escolas das ilhas}

Os encontros formativos foram nomeados dessa forma por partirem de um processo metodológico assumido como exercício da práxis, ou seja, por ser um movimento cíclico (escola-formaçãointervenção), contínuo e de reflexão sobre a prática para os gestores que estão na coordenação das escolas e com a responsabilidade na condução do trabalho pedagógico do cotidiano escolar (FREIRE, 1996).

Os encontros formativos tinham como objetivo desenvolver estudos e o assessoramento à construção do PPP das referidas escolas em parceria com a SEMEC. Nessa empreitada, foram realizados quatro encontros de formação junto aos gestores e alguns docentes, onde focalizamos os desafios e as possibilidades para sua construção, por meio de um caminho metodológico que priorizou momentos coletivos, 
contínuos e por agrupamentos ${ }^{4}$ distintos, que passaremos neste momento a elucidá-los. O conteúdo dos encontros abrangeu questões levantadas pelos participantes tais como: a concepção do PPP, sua construção no interior das escolas, as dúvidas e relatos dos gestores em relação a sistematização, entre outras. Ficou evidente nesse processo, que a troca de experiências pelo agrupamento participante auxiliou na feitura dos projetos e, ao mesmo tempo, os encontros serviram para esclarecer situações do cotidiano vivenciadas na escola e que são comuns para a maioria dos gestores.

O primeiro encontro foi de grande expectativa tanto para o nosso grupo de pesquisa, quanto para os participantes. O público presente lotou o auditório do Campus, que avaliamos ter sido tanto pela importância e anseio de "saber como faz o PPP, quanto pela exigência (meta) estabelecida pela Secretaria de Educação junto as escolas. Portanto, buscamos priorizar as perguntas ao invés das respostas. Assim, a dinâmica foi perguntar: o que é projeto político pedagógico? quais os desafios para a construção do projeto político pedagógico? quais as possibilidades para a construção do projeto político pedagógico? Pudemos avaliar que a dinâmica foi bastante positiva, pois foram muitas as respostas. Diante disso pudemos inferir que os gestores e professores não têm dúvidas sobre o que é o PPP e qual sua importância para o contexto escolar. Mas sem dúvida a maior expectativa estava em relação a possibilidade de orientação de 'como fazer na escola'. Tal necessidade do saber fazer respalda a visão pedagógica atual de que vale a técnica em detrimento do sentido das coisas.

Para argumentar com as questões levantadas, associado ao estudo teórico e de procedimentos para a feitura do PPP, tomamos como referenciais os indicados por Araújo (DRAGO et al., 2010, p. 67-71) ao elucidar que para a construção do PPP é fundamental a compreensão de que:

1 - Todo projeto possui uma intencionalidade. O PPP é definido como norteador das ações educativas escolares, que estão vinculadas a um projeto histórico-social mais amplo.

2 - Refletir sobre o papel político e pedagógico da escola implica em reconhecer a educação como ato político (ou

\footnotetext{
${ }^{4}$ Os agrupamentos foram organizados pelos gestores das escolas e tais escolas formam polos que situam as comunidades das ilhas.
} 
reforça a ideologia dominante ou desvela os mecanismos de dominação). A educação traz em si essa contradição. A educação tem sempre intencionalidade, porque é uma prática social.

3 - Educação é perpassada por valores. O modo como o gestor e o educador se posicionam diante da realidade, como participam da história, como concebem o saber, a relação que estabelecem com os alunos e com a própria comunidade escolar reflete saberes, culturas e valores adquiridos ao longo de sua história de vida.

4 - O PPP traz essas marcas, uma vez que não existe neutralidade no fazer pedagógico.

5 - O termo Projeto Político-Pedagógico nasce nos anos 80 com o intuito de se contrapor à visão burocrática e técnica do planejamento educacional.

6 - Três características do PPP: antecipação do futuro, dimensão utópica e prática social coletiva. Por isso não é produto ou plano como frequentemente é compreendido.

7 - O PPP é a relação dialética entre o instituído e o instituinte.

8 - Não deve ser compreendido, portanto, como mera formalidade que não orienta a prática efetiva da escola.

9 - O PPP apresenta duas perspectivas: como ação regulatória ou técnica ou como ação emancipatória ou edificante.

10 - O PPP numa perspectiva emancipadora traduz: democratização da escola, inclusão, diálogo, cooperação, negociação, participação, autonomia, legitimidade na formação da vontade geral, unicidade e coerência no processo educativo.

11 - A construção do PPP da escola pressupõe diferentes concepções e metodologias de planejamento, conforme quadro abaixo:

12 - "[...] a teoria (plano) deve ser a melhor possível, não caindo, porém, na ingenuidade de imaginar que basta planejar para acontecer: há toda uma luta ideológica, política, econômica, social para ser enfrentada, seja consigo mesmo, com seus colegas de trabalho, com os educandos, com as famílias e com as instituições em geral" (Celso Vasconcellos, 1999). 
13 - Por ser a realidade dialética não há como não conviver com as dificuldades na construção do PPP: a) comodismo por parte dos sujeitos; b) imediatismo; c) perfeccionismo; d) falta de esperança/confiança na instituição; e) formalismo; f) falta de experiência de trabalho coletivo; g) rotatividade das pessoas; h) falta de condições objetivas de espaço-tempo para encontro i) elaboração $e$ acompanhamento; j) falta de exercício democrático na escola. Também há a visão burocratizada de planejamento e a desarticulação entre o projeto e as ações na sala de aula (grifos das autoras).

Assim, através das reflexões filosóficas, sociais, políticas que envolvem a construção do projeto, pudemos acentuar a realidade sociocultural onde estão localizadas as escolas e, ainda, promover uma discussão acerca das identidades e subjetividades que movem o currículo dessas escolas mostrando que o PPP é mais que um documento formal e estático, pois abrange múltiplas dimensões (sociais, econômicas, filosóficas, pedagógicas, administrativas, locais) constituindo-se em documento de identidade da escola.

O segundo momento de encontro formativo, pautou-se no tema: terra amazônica - águas, saberes e floresta. O momento marcou o território do campo (das ilhas) em que se procurou esclarecer o valor sociocultural do 'ribeirinho' e seus modos de vida, no sentido de que a educação do campo é uma forma de ação política e social que busca contribuir com a qualidade de vida dos sujeitos. Nessa direção, a escola precisa ser reconhecida como espaço de reflexão sobre a realidade dos povos do campo, da sua cultura, das suas formas de sociabilidade, do seu trabalho, das suas linguagens e, sobretudo, precisa estar sintonizada com a ideia de um novo projeto de desenvolvimento e que supere o paradigma do capitalismo agrário (Diretrizes Operacionais para a Educação Básica nas Escolas do Campo. Resolução 1/2002 CNE/CEB).

Esse momento de encontro foi marcado pela magia da contação de histórias que retratam a Amazônia paraense; a dinâmica foi utilizar a melodia das águas e cantando assim: "a canoa vai de proa, e de proa eu chego lán". Foi discutido neste espaço de tempo a necessidade de 'amazoniar' a escola para que não percamos o tempo, o gosto, o modo e o amor pela terra Amazônia com suas florestas, suas terras e suas águas,

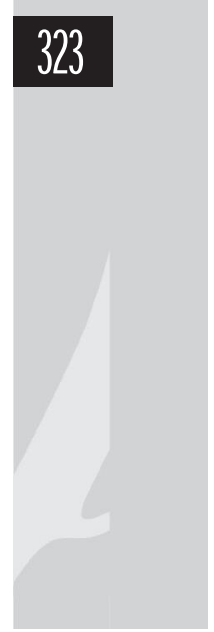


pois "a relação do ribeirinho com o seu tempo-espaço tem uma forma na produção de cultura" (SANTOS, 2007)

Buscamos discutir junto ao coletivo dos gestores e com todos os outros presentes, temas que demonstram que o 'modo próprio do viver ribeirinho' e as relações entre o rio-mar e o cotidiano da travessia até as ilhas, são elementos do processo educativo da escola. Assim, aprender a lidar com o cotidiano das viagens pelos rios até as escolas, saber lidar e dialogar com os modos e temporalidades próprias, com as identidades das crianças e jovens, com os saberes da comunidade deve ser elementos intrínsecos ao currículo escolar, que precisam ser somados ao conhecimento científico. Portanto, não basta compreender os fundamentos teóricos e metodológicos que embasam as práticas educativas atuais, aprender a lidar com o jeito ribeirinho de ser é uma condição fundamental para quem se habilita a exercer a docência numa comunidade ribeirinha dentro da amazônia paraense.

Concomitante às discussões sobre a cultura ribeirinha orientamos os gestores quanto aos instrumentos de organização e elaboração do PPP tais como: o diagnóstico, as metas, os objetivos e as ações frisando também a necessidade de cada escola ter seu plano de trabalho que direcione a condução da elaboração do PPP sob a coordenação dos gestores. Construímos então um roteiro indicativo, com a orientação de que cada escola devia exercitar sua autonomia fazendo as modificações e alterações conforme suas necessidades e demandas do cotidiano.

Concernente ao terceiro e quarto encontros de formação focalizamos a realidade das escolas das ilhas. Por isso, estes aconteceram em escolas de alguns pólos ${ }^{5}$ discriminados pela localização e nomes dos rios e furos, quais sejam: rio Paruru; rio Quianduba; rio Piquiarana e rio Campompema.

Esse movimento de formação nas escolas foi importante para nos situarmos sobre o contexto de 'ilhas' e conhecer o cotidiano da escola, ou seja, pudemos perceber o quanto é complexo e singular a escola localizada às margens dos rios, pois estas lidam com as interseções entre: as temporalidades presentes (o tempo da maré, o tempo escolar, o tempo de

${ }^{5}$ Pela SEMEC as escolas estão organizadas em agrupamentos por aproximação constituindo o que classificam de pólos, como um conjunto de escolas numa mesma área. 
uma rabeta para fazer a travessia até a escola, o tempo do trabalho); a relação necessária entre conhecimento e saber (o conhecimento produzido pela humanidade e a cultura da comunidade); a linguagem e modos próprios (gestos, ritmos, costumes e a sonoridade da natureza); relações com a água (transporte, travessia, tempo, uso, trabalho e brincar), entre outros aspectos que expressam a imbricação territorial (do contexto local) com a escola. Intencionando também reafirmar o quanto essa singularidade espacial é importante para as problematizações e concepções que deve ser essencial, na elaboração do projeto político pedagógico da escola e que passa muitas vezes despercebido.

Foram momentos de grande interação pedagógica juntos aos gestores, em que priorizamos, inicialmente, discutir sobre a ilha e as comunidades. Para apreensão dos pontos de vista, utilizamos como estratégia a construção de mapas que retratassem a geografia local e o saber das águas pelos participantes e nesse mapa, eles apresentavam a redondeza dos rios, furos e os contrastes sociais. Ainda como parte da formação, foi realizado a socialização sobre a construção dos PPP pelos gestores, que culminou com indagações focadas na dificuldade de participação da comunidade escolar e no tempo para a organização da escola para feitura do projeto. Para ajudar na reflexão sobre tais questões enfatizou-se também que a construção do PPP requer um pensar e um agir diferenciados, coletivo, técnico e compromissado com a mudança. Nessa direção, Gadotti (1994) considera real algumas limitações ou obstáculos que a escola enfrenta ao optar por um caminho democrático como parte do projeto político pedagógico, entre os quais destacamos:

- a pouca experiência democrática com participação ativa;

- a mentalidade que atribui aos técnicos como os que pensam e a mentalidade que considera o povo incapaz e que precisa ser dirigido;

- a própria estrutura do sistema educacional que se coloca verticalizado;

- o autoritarismo que se apresenta como força pedagógica no cotidiano educacional; e

- o tipo de liderança que tradicionalmente domina a atividade política no campo educacional: burocrática por dentro e corporativista por fora. 
De outro modo, a feitura de um PPP exige o aprofundamento acerca da função social da escola, o que envolve tratar sobre o cotidiano, a realidade escolar e a comunidade circundante; envolve compreender que a visão da comunidade precisa ser considerada, porém, a estratégia de escuta é diferenciada e com uma linguagem menos pedagógica e mais dialógica. Pensar que cada escola é uma escola singular, conduzirá o PPP por caminhos diferentes e próprios. Essa experiência nos fez refletir sobre nossa visão da educação do campo, e foi construído como resultado de um processo complexo de debate, que exigiu tempo, estudo, reflexão e aprendizagem de trabalho coletivo.

Os encontros formativos constituíram percursos, trocas de experiências e estudos em que os gestores apresentaram concepções, produções teóricas e suas dificuldades com a realidade perfilada. Eles apontaram, em sua maioria, a necessidade de assessoramento contínuo por parte da secretaria de educação para ajudá-los nas construções pedagógicas da escola e, também, demonstraram esforço coletivo e individual na realização da tarefa de construção do projeto político pedagógico com comprometimento educacional e social.

\section{Considerações do processo vivenciado}

Em síntese, essa ação extensionista do grupo de pesquisa focada na construção de PPP por meio de momentos formativos possibilitou aprendizagens diversas.

Foi evidente a importância dos encontros formativos para a construção dos PPP das escolas das ilhas, assim como a iniciativa dos gestores e de professores para a efetivação desse trabalho, mesmo com os contratempos oriundos do cotidiano (tempo, participação, dúvidas) e infraestrutura escolar (materiais, rotatividade dos professores, pouca participação nas formações), porém, os encontros previstos pelo GEPESEED foram todos executados.

Outro fato relevante e que foi esclarecido é que o PPP das escolas do campo só tem sentido e valor político-pedagógico se pensado para ser instrumento a favor da inventividade, da criatividade, de uma sintonia coletiva dos educadores e seja inspiração para:

a) 'outras/novas' formas de dinâmicas de organização e funcionamento democrático das chamadas classes multisseriadas, e não simplesmente pautar sua exclusão. 
b) compor estratégias que traduzam processos de aprendizagem dinamizados pelas vivências pessoais e experiências sociais oriundos da sociodiversidade do ribeirinho, do homem da floresta, do agricultor, do 'campo', do viver.

c) adentrar no saber das águas e da floresta num intercâmbio entre conhecimento e experiência.

d) saber sobre o direito de ter 'escola do campo' próximo às residências dos estudantes, que o calendário precisa ser diferenciado com adequação às fases do ciclo agrícola e às condições climáticas, sendo desenvolvidos por meio de um currículo que considere as diferenças socioculturais das populações atendidas, e, de fato, a oferta de educação seja com qualidade social.

O PPP construído com participação ativa poderá servir para que a escola aprenda a trabalhar no coletivo, valorizando as experiências de cada um dos envolvidos, e se dando conta da importância de articular e por em prática objetivos para uma aprendizagem de qualidade (gestora participante, 2012).

É tarefa político-pedagógica da escola desenvolver ações que contribuam para a efetiva formulação de projetos pedagógicos próprios dos espaços, com ênfase no contexto sociocultural dos estudantes e sua aprendizagem, pois o PPP é a representação das vivências e práticas humanas, sociais e pedagógicas que norteiam o cotidiano das escolas. É um processo de estudo e aprendizagem da realidade em seus diversos momentos (gestora participante, 2012). E ainda, é um trabalho construindo coletivamente, com o intuito de caracterizar a identidade da escola (gestora participante, 2012).

Finalmente, ficou evidente por meio desses encontros que: a) houve avanço na produção escrita dos gestores e professores; b) avaliam a construção do PPP como positivo, pois detectaram problemas na escola e apontam ações especificas; c) fica difícil a construção do PPP quando a escola tem uma rotatividade grande de funcionários (contratados) e que não moram na comunidade, dificultando acompanhar as atividades da escola; d) solicitam a continuidade das formações e de assessoramento por parte da SEMEC; e) os encontros mobilizou para o trabalho coletivo e o comprometimento de todos com a escola.

Mesmo em meio as contradições educacionais a que estamos submetidos na atual conjuntura social do país, acreditamos que a escola pode ser melhor qualificada, o que significa uma experiência pedagógica de compromisso político implicando um cotidiano com educadores comprometidos, menos ausentes, que gostam do que fazem, 
se comunicam com os pais, pensam e organizam as ações; conhecem os alunos e suas problemáticas, discutem e ouvem a realidade de vida onde a escola está situada.

\section{REFERÊNCIAS}

ARROYO, Miguel; CALDART, Roseli S.; MOLINA, Mônica C. Por uma educação do campo. Petrópolis: Vozes, 2004.

BRASIL. CNE/CEB. Diretrizes Operacionais para a Educação Básica nas Escolas do campo. Resolução CNE/CEB, n. 1, de 3 de Abril de 2002.

BRASIL. Diretrizes Complementares para o atendimento da Educação Básica do Campo. Resolução CNE/CEB, n. 2. Brasília/DF, de 28 de Abril de 2008.

BRASIL. Lei n. 9.394, de 20 de dezembro de 1996. Lei de Diretrizes e Bases da Educação/ LDB. Diário Oficial da União. Brasília, 1996.

DRAGO, Rogério; PASSAMAI, Maria Hermínia Baião; ARAUJO, Gilda Cardoso de. (Org.). Projeto político pedagógico da educação do campo. Vitória: PPGED/UFES, 2010.

FREIRE, P. Pedagogia da Autonomia: saberes necessários à prática educativa. São Paulo: Paz e Terra, 1996.

SANTOS, M. R. S. Entre o rio e a rua: cartografia de saberes artísticoculturais emergentes das práticas educativas na Ilha de Caratateua, Belém do Pará. Dissertação de Mestrado. Belém: UEPA, 2007.

VEIGA, Ilma Passos A. Projeto Político-Pedagógico da escola: uma construção coletiva. In: Projeto Político-Pedagógico da escola: uma construção possível. Campinas: Papirus, 1995.

VEIGA, I. P. A. Escola: espaço do projeto político pedagógico. Campinas: Papirus, 2003.

GADOTTI, Moacir. Pressupostos do projeto pedagógico. In: Anais da Conferência Nacional de Educação para Todos, 28/8 a 2/9/1994. Brasília: MEC, 1994. 